\section{INTEGRATING IMPLICIT AND EXPLICIT \\ GRAMMATICAL PERSPECTIVES ON THE ACQUISITION OF THE ENGLISH ARTICLES: AN ACTION RESEARCH ${ }^{1}$}

\section{Nattama Pongpairoj ${ }^{2}$}

\begin{abstract}
Articles in English have always been a persistent grammatical problem for the Thai learner. A possible reason for this may be indirect interference, as a similar syntactic distinction involving definiteness and referentiality, does not exist in Thai. How to remedy this problem in second language acquisition is quite a difficult but challenging task.
\end{abstract}

The purpose of this study is to investigate the positive effects of integrating explicit grammar, a form-based approach, and implicit grammar, a function-based approach, in teaching English articles. It will be argued that such an integration, in comparison with explicit grammar alone, can lead the learner to greater achievement. This learning method enables the learner to recognize both form and function in authentic texts concurrently.

\footnotetext{
${ }^{1}$ Presented at the International Conference on Language, Education and Diversity, University of Waikato, New Zealand, 26-29 November 2003.

${ }^{2}$ Assistant Professor, Department of English, Faculty of Arts, Chulalongkorn University, Bangkok.
}

The pedagogical value of the study is in shedding light on the advantages of adopting an integrative strategy to teach articles to non-native speakers of English.

\section{Introduction}

One of the most problematic English grammatical categories known observationally to cause persistent difficulties and inaccuracies for Thai learners is the article system: 'a,' 'an,' 'the.' Even though there are only three articles in English, they tend to pose serious acquisition problems for Thai learners. Choosing the right article for a noun or noun phrase is quite a challenging task as there is no one-to-one correlation between English and Thai and no clear cut rules for use in English. Master (1994) states, "The simplicity of the words that make up the [article, my addition] system masks the complexity of the rules for nativelike usage"(229). Lekawatana, et al. (1968) note, "Mistakes involving the misuse or omission of articles in English are probably more prevalent than any other single grammatical error in the speech of Thai students...The use of articles is not a simple, straightforward procedure" (96). What's more, these second language learners have studied rules for English article use since they were young. Still, they do not completely grasp their correct usage. English language teaching professionals who work with Thai learners, as well as Thai learners of English themselves, often encounter this complicated and confusing problem, which is worth further investigation.

One cause of problems in SLA is interference, the existence of different linguistic systems between the native 
and the target languages, which leads to interlingual errors. Indirect interference, or the error-causing process which occurs when a linguistic category in the foreign language has no parallel in the mother tongue, also plays a role in causing problems for second language learners. As learners cannot grasp items in the mother tongue equivalent to those in the second language, errors arise. Menachem and Batia (1983) believe that the indirect type of $\mathrm{L} 1$ interference "occurs when the learner tries to cope with an L2 category nonexistent (or virtually non-existent) in his L1"(31). In his studies of Czech learners, Dušková (1969) found that as articles are linguistic features that do not exist in Czech, the problem of indirect interference is more complicated than a direct one. He states, "There being no articles in Czech, Czech learners possess no frame of reference which might facilitate comprehension and mastery of their uses" (221), and "The learner has no frame of reference to which he can relate his expression in the foreign language. The teacher is faced with the problem of developing intuition for the foreign language category independently of the mother tongue" (232) and in this way "The articles remain the last sphere in which Czech speakers continue to make occasional errors even in the case of a nearnative command of English" (232). In discussing the problems of Thai learners in acquiring the English articles, Pongpairoj (2002) says, "The cause of this type of error can be determined by the absence of the system in the native language of the learners" (89).

The problem of acquiring the system of English articles can then be traced back to the fact that the choice of English articles concerns properties of nouns: singularity vs plurality, countability vs non-countability. What is more complicated is English morphologically marks the property of definiteness while Thai does not. Since definiteness involves an intuition of semantic aspects, attempts to rationalize functions and usage of articles are needed.

In view of this problem, it should be realized that a number of Thai learners learn English articles through explicit grammar. In the traditional lesson, a set of rules for English article usage is presented to them. These rules are memorized, and explicit examples on particular grammatical points are used so that the rules can be applied. This learning method is beneficial but does not seem to lead to complete achievement in the acquisition of the English article system since, as widely noted, after having learned the system for many years, Thai learners still make errors and hesitate in using articles.

Another type of teaching is through Implicit Grammar, whose principle is usage of linguistic items for communicative aims. The notion is related to Functional Grammar. Richards, in his preface to Lock's Functional English Grammar, defines functional grammar as "an approach to understanding grammar that focuses on how language works to achieve a variety of different functional and communicative purposes. The emphasis is then on how the purpose for which language is used and the contexts in which it appears affect the choices speakers and writers make" (ix).

This research concentrates on errors in English article usage committed by Thai learners. These errors will be analyzed, and it will be argued that integrating 
explicit and implicit grammatical perspectives is more effective in SLA than only form-focused instruction.

First, the objectives of the paper will be listed, followed by a review of English articles and two types of grammar implicit and explicit. Then the data will be analyzed to show the effectiveness of learning articles through a combination of the two approaches, rather than only through explicit grammar.

\section{Hypothesis}

Integrating implicit and explicit grammatical perspectives leads to greater achievement in the acquisition of English articles by Thai learners than explicit grammar alone.

\section{Objectives}

The study aims at the following:

3.1 Exploring and analyzing the subjects' performance on English articles in decontextualized items and contextualized items;

3.2 Using explicit grammar instruction to teach English articles to one subject group and integrating explicit and implicit grammar for the other group;

3.3 Exploring and analyzing the subjects' performance on English articles in decontextualized items and contextualized items after the learning period; and

3.4 Comparing and contrasting pretest and post-test results of the two groups to investigate the acquisition of English articles so that the findings lead to an insight into which type of learning is more effective.

\section{Literature Review}

\subsection{Grammar Teaching Approaches}

This part investigates the two grammar teaching approaches used in the experiment: the Explicit Grammar Teaching Approach and the Implicit Grammar Teaching Approach.

\subsubsection{Explicit Grammar Teaching Approach}

This type of grammar teaching approach is an approach whereby a linguistic category is directly explained in terms of a set of discrete formal rules. As Odlin (1994) states, "To most people, the term grammar suggests dos and don'ts"(1). As the grammar is in the foreground and the main focus of the method is on form and accuracy, learning acquisition is conscious. The approach is, according to Lee and Yan (2001), "form-focused and accuracyoriented" (1). Since the objective is to develop the learner's grammatical accuracy, the material is decontextualized and grammar is taught in isolation. The grammar, thus, is of sentence-level structures. The emphasis in explicit grammar is on rule explanation, structural practice, and corrective feedback such as drills on structural patterns. Sentences are thus made up to illustrate different grammar rules. Learning input is presented, followed by practice and form-focused materials. Yip (1994) asserts, "Grammatically structured syllabi still present explicit grammar paradigms with limited exposure to authentic input" (124). Explicit grammar is a deductive approach since rules are given before practice. 
Odlin (1994) discusses Master's work in which students were shown to benefit from explicit grammar instruction. Yip also discusses studies in favor of the explicit grammar teaching approach: White (1991) found that French learners of English performed dramatically better on adverb placement given "formfocused" instruction; Carroll and Swain (1991) found explicit grammar effective in Spanish learners' acquisition of dative verbs. Lee and Yan (2001) note, "Due to the inherent complexity of certain grammatical structures, rule explanations seem to help learners understand faster and better" (6).

\subsubsection{Implicit Grammar Teaching Approach}

In contrast with the former approach, the principle behind this type of teaching is communicative and the focus is on meaning and fluency. The primary objective is to enable learners to understand what grammatical rules are and how language elements can enhance functional and communicative aims. Linguistic elements are given in a context drawn from real world sources rather than in isolation, and "learners are to work out the implications of rules and apply them creatively" (Yip 1994: 134). This approach is compatible with Krashen's Input Hypothesis, which states that comprehensible input is necessary for second language acquisition. It can, thus, be stated that grammar is tied to texts that go beyond one single utterance - an extended discourse - and the learning process is unconscious. The objective is to develop fluency in communication. The materials as well as language tasks are authentic and contextualized so that learners can improve their language competence naturally and, in this way, grammar rules can be internalized.

Yip (1994) writes that this approach enriches linguistic exposure, which facilitates second language improvement. The function-based practices provide the learner with opportunities to apply grammatical structures to use and meaning concurrently. Lock (1995) also expresses a similar idea, remarking, "The primary aim of a functional grammatical analysis is to understand how the grammar of a language serves as a resource for making and ex-changing meanings" (3). Richards, in his preface to Lock's Functional English Grammar, states that "The emphasis of functional grammar is thus on how the purpose for which language is used and the contexts in which it appears affect the choices speakers and writers make" (ix). Little (1989) argues that the grammar of a language has a real use; it is not just a matter of forms and structures. Grammatical points are, therefore, tied to the texts in which they occur. Little claims that an implicit grammar approach requires learners to analyze how linguistic categories are related to one another in terms of use. He also speaks of a communicative principle in which "Form should always be subordinated to meaning" (106). This learning approach then is concerned with the beneficial role of authentic texts for learners. Lee and Yan (2001) state, "Meaning-focused materials should not be completely excluded from classroom use." Emphasis, is placed upon the authenticity of the language the learner is exposed to. Therefore, implicit grammar is an inductive approach in which rules are generalized after the activities. 
The differences between the two grammar teaching approaches can then be clearly seen. Explicit grammar tends to focus more on relationships between
To recapitulate, explicit and implicit grammatical approaches differ in the following characteristics:

Table 1: Differences between Explicit Grammar and Implicit Grammar

\begin{tabular}{|c|c|}
\hline Explicit Grammar & Implicit Grammar \\
\hline 1. rule-oriented & 1. function-oriented \\
\hline 2. form and accuracy & 2. meaning and fluency \\
\hline 3. conscious learning & 3. unconscious learning \\
\hline 4. decontextualized materials & 4. contextualized materials \\
\hline (form-focused materials) & (meaning-focused materials) \\
\hline 5. sentence-based approach & 5. text-based grammar approach \\
\hline 6. deductive & 6. inductive \\
\hline
\end{tabular}

Each approach seems to have a different perspective. There are distinct arguments in favor of both approaches. For example, Sunaryo (2001) claims that implicit grammar can lead the learner to communication but without acceptable accuracy. According to Lock (1995), in explicit grammar, there is an exclusion of the use of structural rules in authentic contexts in present-day English. Yip (1994) claims that with implicit grammar, "Comprehensible input is certainly necessary but not sufficient to bring about successful acquisition" (125, my emphasis).

Sunaryo (2001) takes a less extreme stance, noting, "A dilemma emerges as focusing on communicative activities brings failure in the accuracy, whereas focusing on accuracy (the grammar) does not guarantee the learners to be able to use it for communicative purposes". She argues that, in order to

structures and less on meaning and context, while implicit grammar concentrates primarily on meaning expressed through language structures. keep the right proportion between form (accuracy) and meaning (fluency), traditional grammar is indispensable as "grammar is the framework through which meaning is expressed" (50).

Different studies support the idea of using one approach to supplement the other. Several ideas call for explicit grammar to be incorporated in implicit grammar. But according to Yip, other views give priority to explicit over implicit grammar. She says "Several research findings cast doubt on the strong no-grammar position and lead to a reconsideration of the possible roles for grammar instruction" (124). She raises Harley and Swain (1984)'s study of the French immersion program that questioned whether only comprehensible input is sufficient in second language acquisition as the subjects "showed notable grammatical deficiencies" (124). Schachter (1991)'s study on the acquisition of the verbal system also supported that same notion. Other supporting views for explicit grammar also include that of Richard (1996), who states, "Grammar is not an optional addon to communication. It lies at the very 
heart of communication" (267). Ellis (1996) claims that form-based instruction "speeds up learning in the long term and helps to prevent the kind of grammatical fossilization found in naturalistic adult learners" (169). Master cites Zobl's claim that an awareness of forms could be significant in acquiring articles among learners.

Opposing views have also been expressed on applying not just explicit but implicit grammar in SLA. Montgomery and Eisenstein (1985), quoted in Lightbown and Spada (1995: 309), reveal an interesting finding: "Combination of form-oriented and meaningoriented language teaching was more beneficial than form-oriented teaching alone" (329). Similar conclusions were drawn by Allen, Swain, Harley, \& Cummins (1990) on French L2 programs for children.

Explicit and implicit grammar should then be integrated, and a proper proportion of each approach can render its own pedagogic value. Lee and Yan (2001) state, "There have been studies on using an integration of explicit and implicit grammar as an advantageous approach and that the two approaches should be complimentary to each other rather than mutually exclusive" (21). Lightbown and Spada (1995) found in one study that "classrooms that provide a focus-on-form within contexts of meaningful communication work better than either those that avoid formfocused instruction altogether or those that emphasize form-focused instruction to the virtual exclusion of communicative activities" (310). In using a mixture of both paradigms, the teaching and learning are conducted within a text-based approach integrated with a grammar-based approach, and it is essential that there be a balance between accuracy and fluency. Chun, et al. (2001) claim learners who do not learn a second language in an environment rich in that language "need consciousness-awareness or form-focused activities/materials to help them internalize language rules and patterns so they can work on the meaningfocused tasks/activities more confidently" (21). To sum up, the focuson-form approach enriches the learner's awareness of a particular grammatical point; the focus-on-function approach encourages the learner to understand how to use form in genuinely communicative texts.

An integration of both explicit and implicit grammatical approaches is a methodological option that tries to maximize both accuracy and fluency in language acquisition. Language input is given to the learners, who can incorporate what they have learned in actual usage. Lee and Yan (2001) note, "Empirical studies show there is a necessity to integrate form-focused treatments into meaning-focused communicative tasks" (3). Johns has devised the figure below to show the relationship between form and function in language: 


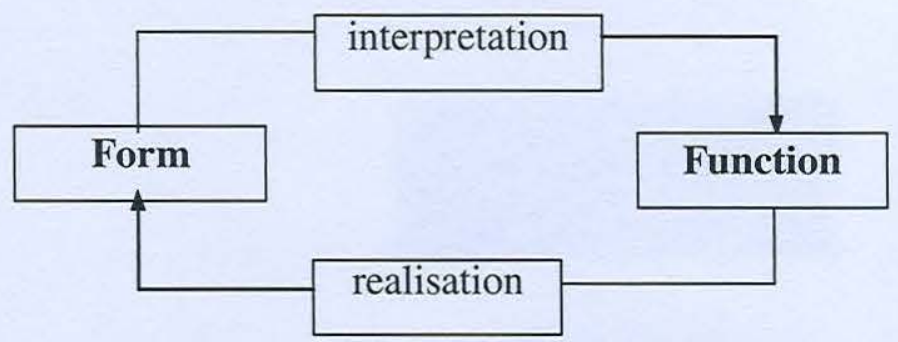

Figure 1: The relationship between form and function in language (Johns, 1994:294)

Form and function are interrelated in such a way that the knowledge of form can lead to an interpretation of usage while a knowledge of function enhances the generalization of form. In this way, the learner can exercise grammatical aspects in relation to authentic contexts. However, the proportion of implicit and explicit grammatical approaches has to be taken into consideration.

Insights into teaching grammar using the two interrelated strategies as an effective approach, then, are to be explored.

\subsection{English Articles}

\subsubsection{Perspectives on the English Articles}

In terms of the traditional approach, general treatments have been devoted chiefly to memorizing rules. Examples of traditional rules for English article usage are as follows:

\section{The indefinite article}

The indefinite article a or an is used:
- Before a singular noun which is countable (i.e. of which there is more than one) when it is mentioned for the first time and represents no particular person or thing:

I need a holiday.

They live in a bungalow.

- Before a singular countable noun which is used as an example of a class of things:

A car must be insured $=$ All cars $/$

Any car must be insured.

- With a noun complement. This includes names of professions:

He is a doctor.

She is a teacher.

He became an actor.

- In certain numerical expressions:

a dozen

a quarter

a thousand

a great many

- In expressions of price, speed, ratio etc.:

5p. a kilo

sixty kilometres an hour 
- In exclamations before singular, countable nouns:

What a hot day!

What a pretty girl!

Such a pity!

- a can be placed before $\mathrm{Mr} / \mathrm{Mrs} /$

Miss + surname:

a Mr. Smith

a Mrs. Smith

a Miss. Smith

a Mr. Smith means 'a man called Smith' and implies that he is a stranger to the speaker.

Mr. Smith, without a, implies that the speaker knows Mr. Smith or knows of his existence.

\section{The definite article}

The definite article is used:

- Before nouns of which there is only one, or which are considered one:

the earth

the sea

the sky

the weather

the North Pole

- Before a noun which has become definite as a result of being mentioned a second time:

His car struck a tree; you can still see the mark on the tree.
- Before a noun made definite by the addition of a phrase or clause:

the girl in blue

the man on the donkey

- Before superlatives and first, second,etc. and only, used as adjectives or pronouns:

Mont Blanc is the highest mountain in Europe.

- the + singular noun can represent a class of animals or things:

The whale is in danger of becoming extinct.

- the is used before certain proper names of seas, rivers, groups of islands, chains of mountains, plural names of countries, deserts:

the Arctic

the Atlantic

the Alps

the Netherlands

the U.S.A.

the is also used before names consisting of noun + of + noun:

the Cape of Good Hope

the Gulf of Mexico

the is used before names consisting of adjective + noun (provided the adjective is not east, west etc.): the Gold Coast

the Ivory Coast

the New Forest 


\section{Omission of the definite article}

The definite article is NOT used:

- Before abstract nouns except when they are used in a particular sense:

Men fear death

But The death of the Prime Minister left his party without a leader.

- After a noun in the possessive case, or a possessive adjective:

The boy's uncle $=$ the uncle of the boy

Before names of meals:

The Scots have porridge for breakfast.

But The wedding breakfast was held in her father's house.

- Before parts of the body and articles of clothing:

She seized the child's collar.

I patted his shoulder.

could be expressed:

She seized the child by the collar.

I patted him on the shoulder.

Omission of the before home and before church, market, school, hospital, etc.

home

When home is used alone, i.e. is not preceded or followed by a descriptive word or phrase, the is omitted:

He went home.

She left home.
They got home late.

But when home is preceded or followed by a descriptive word or phrase, it is treated like any other noun as regards articles and prepositions:

We went to the bride's home.

For some years, this was the home of your queen.

chapel, church, market, college, school, hospital, court, prison, work, sea, bed

These nouns are used without the when they are visited or used for their primary purpose:

We go to church to pray

to school to study

to hospital as patients

Similarly we can be in prison/court as prisoners in hospital/bed as patients When these places are visited for other reasons the article is used:

I went to the church to see the carvings.

He comes to the school sometimes to speak to the headmaster.

(Adapted from Thomson and Martinet, A Practical English Grammar. 1980: 1-7.)

The rules above are stated in definiteness and are a prescription of the surface structure of the English articles. To the second language learner they also seem somewhat arbitrary, and without sufficient grounds to account for the underlying reasons behind them. 
As mentioned, Thai learners often make errors on English articles. According to Pongpairoj (2002), the problem results from "morphosyntactic interference blending with incorrect semantic aspects" (Pongpairoj 86). Thus, semantic notions exist beyond words themselves, and the difficulty lies in the fact that distinctive concepts are marked in Thai and English. According to the finding, "It is probable that the learners fail to acquire competence in the semantics of the English language. Semantic distortion, as a result, occurs" (Pongpairoj 86). The concept of definiteness and referentiality do not exist syntactically encoded as semantic attributes in Thai at all. This notion is related to Sapir's and Whorf's linguistic relativity hypothesis, widely known as the Sapir-Whorf hypothesis, whose principle is that distinctive conceptual perspectives are inherent in different languages. Hung states, "It is a truism to observe that, in learning grammar, learning the morphosyntactic form or structure is primary; equally important is the semantic property/meaning of the structure" (9). English and Thai are characterized by two distinct thought patterns. There is, therefore, a semantic integration ingrained in article usage. Murugaiyan (2001) expresses a similar idea, noting, "The teacher of English grammar is required to present sociological, semantic and discourse factors along with the structures" (33). In her study, Pongpairoj (2002) found that, among grammatical categories with semantic aspects involved, articles account for more than half of the errors committed $(52.46 \%)$. In discussing Little's idea that the semantic properties of words often have syntactic ones that are closely associated, Odlin (1994) states that this notion can facilitate second language learners' compre- hension of grammar at the sentence and text levels.

The treatment of the system of articles from a functional perspective is divergent from the traditional approach. Tarone and Parrish (1995) discuss Huebner (1983)'s presentation of articles from a semantic and pragmatic standpoint.

Huebner analyzes the semantic and pragmatic functions of noun phrases in terms of two distinctive binary features:

[ $+/$ - information assumed known to the hearer] $([ \pm \mathrm{HK}])$

[+ I - specific referent $]([ \pm$ SR $])$

(Huebner 1983: 287)

These two binary features lead to four types of noun phrase:

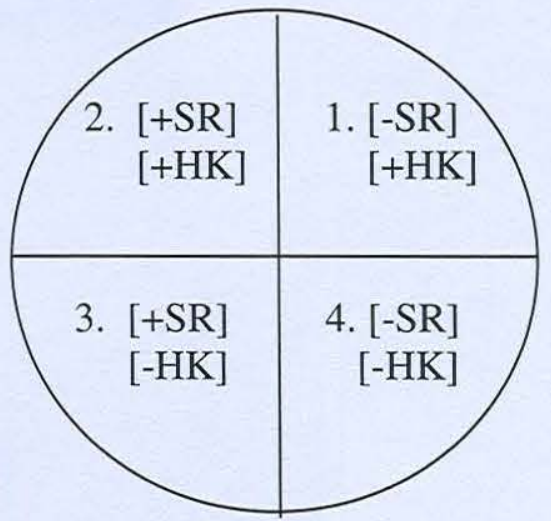

Figure 2: Semantic Wheel of Noun Phrase Types

(Huebner 1983: 287)

Huebner analyzes article use through functions of the articles, not through their use or non-use. His system of analysis is based on the principle that article use depends on the semantic and pragmatic functions of each noun phrase and so the articles are used according to each semantic class of noun phrase. Because 
each noun phrase belongs to one of the type categories, we can assign it a semantic function by considering the said features.
Tarone and Parrish (1995) give examples of each noun phrase type and their semantic function in Standard English as follows:

Table 1. Four NP type Categories and their Semantic Functions in Standard English

1. [-Specific Referent] [+Hearer Knowledge] ("Generics")

Standard English: definite, indefinite, 0

e.g., The lion is a beautiful animal.

e.g., $\underline{0}$ Lions are beautiful animals.

e.g., $\underline{\text { A }} \underline{\text { lion is a beautiful animal. }}$

2. [+Specific Referent] [+Hearer Knowledge]

Standard English: definite article

a. Unique referent or conventionally assumed unique referent; e.g., The Pope

b. Referent physically present; e.g. Ask the guy over there.

c. Referent previously mentioned in the discourse:

e.g., A. So he married a woman from England.

e.g., B. Yes, the woman's from London.

d. Specific referents assumed known to the hearer:

e.g., He went over to the bookstore.

3. [+Specific Referent] [-Hearer Knowledge]

Standard English: indefinite article, 0

a. First mention in a discourse of [+SR] NP which is assumed not known to the hearer;

e.g., Dad gave me a car.

b. First mention of [+SR] NP following existential have and assumed not known to the hearer;

e.g., Our house has a garage.

4. [-Specific Referent] [-Hearer Knowledge]

Standard English : indefinite, 0.

a. Equative noun phrases;

e.g., He's a nice man.

b. Noun phrases in the scope of negation;

e.g., I don't see a pencil.

c. Noun phrases in the scope of interrogative;

e.g., Do you see a pencil?

d. Noun phrases in irrealis scope;

e.g, , If I had a million dollars, I'd buy a big yacht.

(Tarone and Parrish 1995: 288) 
It can be noticed the noun phrases are classified according to the semantic aspects of each type and articles are an integral feature that allows the grammar approach to be function-based.

Nevertheless, the classifications do not include proper names, idioms, and commonly-used expressions such as "in the morning." "go home," and "in the future" which, Tarone and Parish note, seem to be learned as formulae.

Quirk et al (1972) explore article use in a similar aspect. They investigate the system of articles in terms of referentiality (specific/generic) and definiteness (definite / indefinite).

Givón (1984) deals with the matter of definiteness and referentiality extensively. His definitions of both definiteness and indefiniteness are as follows: (His numbering is in brackets):

[28] Indefinite: "Speakers code a referential nominal as indefinite if they think that they are not entitled to assume that the hearer can - by whatever means - assign it unique referential identity".

Definite: "Speakers code a referential nominal as definite if they think that they are entitled to assume that the hearer can - by whatever means assign it unique reference" (399).

He further states that definiteness exhibits discourse features and "this universe of discourse is constructed or negotiated between speaker and hearer, and communication then refers to states, events or individuals within that constructed world" (388).

Christophersen (1939) posits the term "explicit contextual basis" to refer to the situation where the form with the indefinite article is given first and the term "implicit contextual basis" to refer to that where there is not any form with the indefinite article but it is clear between the speaker and the hearer what is meant. He gives the following examples "Having talked about a book, one can say the cover, the author, the publisher, etc. without first saying a cover, an author, a publisher, etc" (8). The analysis, therefore, concerns an entity explicitly or implicitly introduced. It is, thus, the contextual knowledge that determines the usage of the indefinite or the definite article.

Referentiality is concerned with shared knowledge between the speaker and the hearer. The speaker's intention to refer to some individual is a significant aspect in comprehending referentiality. This facet of referentiality in language is related to the fact that reference and the universe of discourse are related. Givón also treats the matter of referentiality as a semantic aspect, calling his approach to referentiality "inherently a feature of propositional semantics" (423).

Givón gives the following examples of the notions of binary features : definiteness and referentiality on the use of articles. His numbering is in brackets.

\section{[11] a. John is looking for the book.} (REF,DEF)

\section{b. John is looking for a book.} (INDEF)

(i)...that his mother gave him. (REF, INDEF)

(ii)...on psychics; any psychics book will do. (NON-REF, INDEF)

(Givón 1984: 393) 
As for entities with regular referential and definite properties like "the sun," "the moon," the sky," "the earth," etc., they are in what Givón calls "the permanent file", holding "referentially unique physical or cultural entities." (399). The fact that the speaker and hearer share these permanent-file referents allows for easy accessibility to the file. Srioutai (2001) expresses a similar idea, stating that, in such cases, "One possible referent can be intended in whatever situation it occurs" (158). Shared knowledge of the existence of an entity in a culture, therefore, plays a crucial role in the choice of the article the.

Concerning set phrases with articles or what are called collocations or "any recurring sequences of words" (Sinclair 1985: 217), Kennedy (1990) remarks there have been claims from a number of researchers that collocations are "overwhelmingly pervasive" (217) and that emphasis has been placed on authenticity. He talks about collocations and second language acquisition as follows:

The extent to which collocations occur also suggests that it may be possible to teach some of what has usually been considered as grammar in terms of vocabulary. Thus, for example, at the present time can be considered from a grammatical viewpoint to be a prepositional phrase, or it can be viewed as a lexicalized unit which is often synonymous with the word now... Traditionally and conventionally, regularity in language has been seen primarily in terms of rules of grammar (and discourse), and in vocabulary choice. In the last decade, however, a number of researchers have explored the nature of collocations as a particular type of regularity - the occurrence of particular sequences of words in language use by first and second language learners.

Kennedy (1990: 216)

Collocations with English articles are pervasive. The functional approach could incorporate the learning of these collocations through exposure to authentic language use. Sinclair states "What text-based collocational studies do suggest is that the description of grammar is, from the teacher's point of view, an essential part of methodology, but it needs to be based on more than the orthodox grammatical and lexical description" (228-9). Therefore, traditional grammar cannot account for explanations of collocations, which are formulaic.

Articles collocate with some preceding and following words or word sequences which are lexicalized as a single unit and possess a strong sense of belonging together. Kennedy (1990) talks about collocations thus: "It does seem, nevertheless, that some items that have usually been considered pedagogically from a grammatical perspective can be treated more as vocabulary" (227). One approach to learning collocations is absorption through language experience.

To sum up, articles can be learned from explicit grammar involving rules as well as from implicit grammar using an integration of definiteness and referentiality.

\subsubsection{Errors in the Use of English Articles}

Errors in the use of English articles are various. Researchers have devoted considerable attention to English article 
use and verify the fact that problems of using articles in English usually arise among second language learners. For example, Dušková (1969) studied article usage of Czech learners and found many recurring problems. Similarly, Kok's (1986) study of Malay secondary students revealed the same problems.

Studies have dealt extensively with the usage of English articles. Kok identifies three problem areas of article use: wrong choice of articles, unnecessary insertion of articles, and omission of articles. Pongpairoj's (2002) research on Thai undergraduate learners' errors in English writing confirms the same occurrences although the terms used are somewhat different: misuse of articles, unnecessary articles, and missing articles. Ubol (1988) also finds three common problems of article usage: omission, unnecessary inclusion, and wrong selection. Dušková's findings of article errors among Czech learners reveal identical problem types. Srioutai (2001), in a study of errors made by Thai learners, classified the problems into: omission of the, the/a used instead of $\varnothing$, and $a$ used instead of the and vice versa. The frequency of these errors is possibly due to over emphasis on rules. Second language learners learn how to use the English articles from a number of rules and exceptions without a real understanding of the semantic and/or pragmatic features conveyed by the articles.

\section{Methodology: Data Collection and Scoring Procedures}

The subjects are first-year students of the Faculty of Arts, Chulalongkorn
University, taking 2202111: English 1, a required course for freshmen. In this course, students are divided into groups of approximately 22-23, randomly selected based on their registration numbers. The classes meet three times a week for 5 class hours.

As for the testing instrument, to assess performance of the subjects in the use of English articles, a 30-minute pretest on English articles was administered to 4 groups without prior notice so that the results would reflect the subjects' spontaneous knowledge. The test consisted of 2 parts, totalling 85 items: a decontextualized part (the discretepoint grammar test or the isolated sentence part) consisting of 50 items: 'filling in the blanks' and 'circling the best answer', and a contextualized part consisting of 35 items: 'completing dialogues' and 'filling in the blanks to complete a story' (see appendix 1). The testing instrument was designed this way in order to see how the subjects did on contextualized and decontextualized items covering a wide range of article use: the definite, indefinite and zero articles. Scores were assigned by allocating one mark for each correct answer to determine the accuracy level of article usage for each student. The number of incorrect instances was divided by the total number of items to calculate the mean.

Out of the four groups, two whose mean scores were approximately the same were selected to proceed with the experimental process.

Immediately after the pretest, one group was taught the target category using explicit grammar, while the other received instruction based on an integration of both explicit, form- 
focused, and implicit, function-focused grammar. The former is labeled the control group and the latter the experimental one. Classes meet 3 times a week ( 1 one-hour class period and 2 two-hour class periods per week). Approximately 15 minutes of a one-hour class period and 30 minutes of a twohour class period were spent on teaching English articles. As for the experimental group, the treatment was a blending of rules and usage of the articles. The subjects practiced using articles through both decontextualized and contextualized activities and exercises while in the control group the emphasis was on memorizing rules of English article usage and the activities and exercises given were based on this. The instruction was conducted for 5 weeks. In addition, there were also assignments. Each group was taught by an EFL teacher with extensive experience teaching English grammar to Thai students.

The 30-minute post-test (see appendix II), whose number of parts and items correlated with that of the pretest, was conducted after 5 weeks of instruction to determine the effects of explicit grammar instruction and a mixture of both traditional and text-based instruction assignments. Different but comparable questions were used and scored in the same manner as in the pretest. Then, pre-test and post-test scores were compared to determine if students who underwent both types of instruction made significant improvements in using articles.

\section{Results and Discussions}

In terms of statistical analysis, the results of the pretest and post-test can be summarized as follows:

\subsection{Results of the pretest in the four groups}

In order to find subject groups whose performance on the English articles was approximately of the same level, 4 student groups were asked to do the pretest.

Results of the pretest in the 4 groups are:

Table 2 : Results of the pretest: mean and standard deviation

\begin{tabular}{|c|c|c|c|c|}
\hline \multirow{2}{*}{ Groups } & \multicolumn{2}{|c|}{ Decontextualized part } & \multicolumn{2}{c|}{ Contextualized part } \\
\cline { 2 - 5 } & Mean (\%) & S.D. & Mean (\%) & S.D. \\
\hline 1 & 80.1 & 3.2 & 90.9 & 5.3 \\
\hline 2 & 75.4 & 7.7 & 87.5 & 9 \\
\hline 3 & 75.6 & 7.7 & 88.6 & 10.4 \\
\hline 4 & 78.6 & 7.8 & 90.6 & 8.7 \\
\hline
\end{tabular}




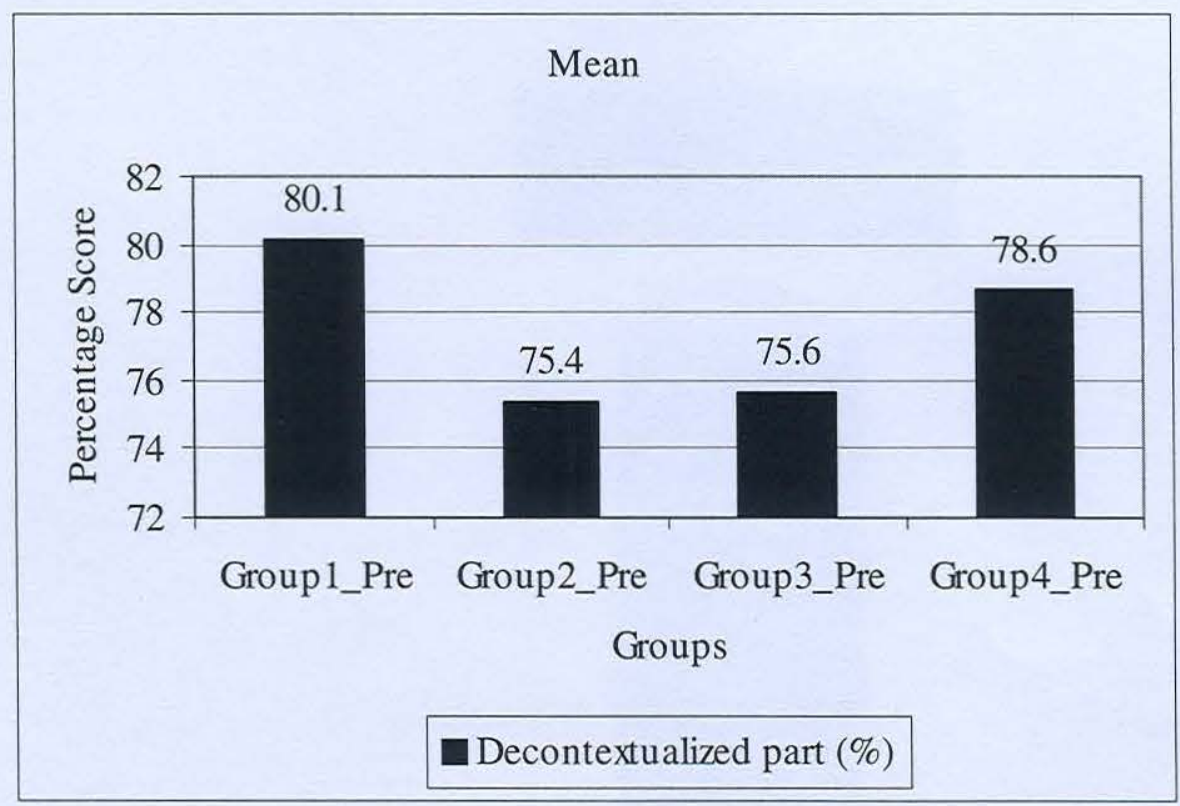

Figure 3: Results of the mean pretest scores: decontextualized part in graph form

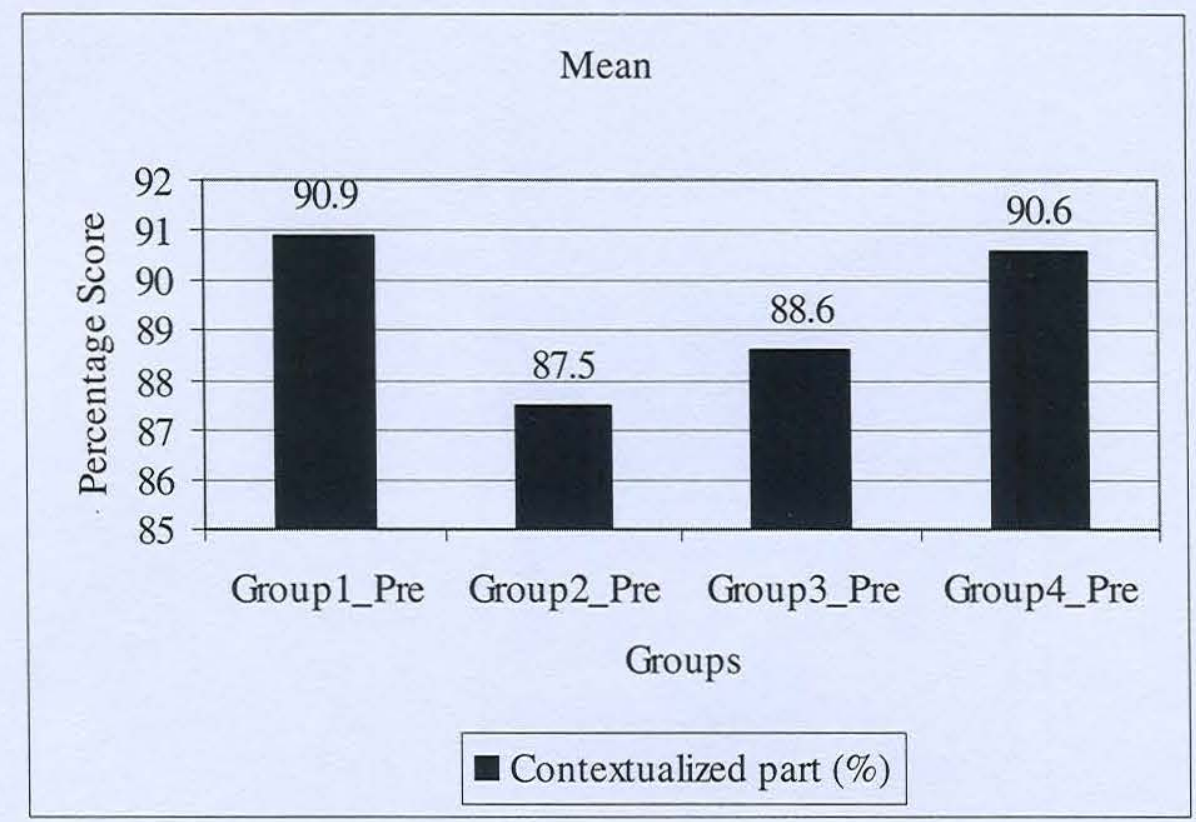

Figure 4: Results of the mean pretest scores: contextualized part in graph form 
It can be seen that the performance of groups 2 and 3 was very similar. That is, group 2's mean percentage score on the decontextualized part was $75.4 \%$ (S.D. $=7.7$ ), compared with $75.6 \%$ (S.D.=7.7) for group 3, while the scores of the other two groups were further apart: $78.6 \%$ (S.D. $=7.8$ ) and $80.1 \%$ (S.D.=3.2). As for the contextualized part, the scores for groups 2 and 3 scores were also close to each other at $87.5 \%$ (S.D. $=9$ ) and $88.6 \%$ (S.D. $=10.4$ ) respectively whereas those of the other two groups were $90.6 \%$ (S.D.=8.7) and $90.9 \%$ (S.D. $=5.3$ ). The standard deviations shown in the decontextualized part for the two groups were exactly the same and in the contextualized part they were not very far apart. The two groups, then, were chosen as the groups in the experiment: group 2 as the control group and group 3 as the experimental one.

What is noticeable is that all of the subjects did better on the contextualized part than the decontextualized one. This may stem from the fact that context helps a great deal in choosing articles. In the decontextualized part, there is no or not much context and the subjects have to rely on rules, many of which are haphazard.

\subsection{Results of the post-test}

After the 5-week experimental teaching period, the subjects were assigned to do the post-test.

Results of the post-test, compared with those of the pretest, are as follows:

Table 3: Comparison of pretest and post-test score percentage of the groups $2 \& 3$

\begin{tabular}{|c|c|c|}
\hline & Decontextualized part (\%) & Contextualized part (\%) \\
\hline Group2 (Pre) & 75.4 & 87.5 \\
\hline Group2 (Post) & 79.6 & 75.5 \\
\hline Group3 (Pre) & 75.6 & 88.6 \\
\hline Group3 (Post) & 79.8 & 95.4 \\
\hline
\end{tabular}




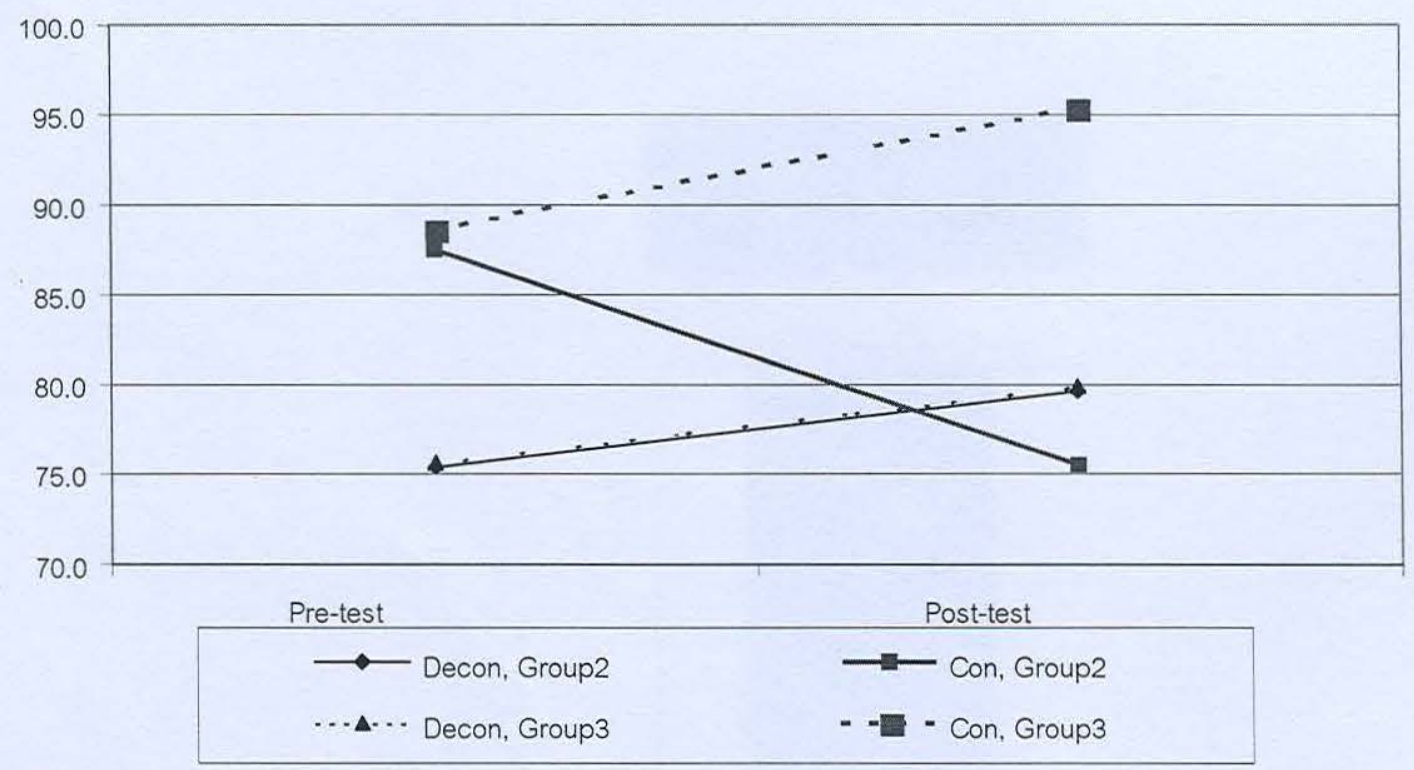

Figure 5: Comparison of pretest and post-test scores in percentage of groups A \& B

The results show that after 5 weeks of instruction, in group 2, the mean scores in the decontextualized part increased to $79.62 \%$ compared with $75.43 \%$ in the pretest while scores in the contextualized part decreased from
$87.48 \%$ to $75.51 \%$. In contrast, for group 3, article accuracy in the post-test was higher than in the pretest in both parts: $75.57 \%$ to $79.83 \%$ in the decontextualized part and $88.57 \%$ to $95.4 \%$ in the contextualized one.

Table 4: Results of the pretest and post-test: decontextualized part /

\begin{tabular}{|c|c|c|c|}
\hline & & Group 2 & Group 3 \\
\hline \multirow{2}{*}{ Mean } & Pretest & 75.43 & 75.57 \\
\hline & Post-test & 79.62 & 79.83 \\
\hline \multirow{2}{*}{ S.D. } & Pretest & 7.75 & 7.67 \\
\hline & Post-test & 5.75 & 3.81 \\
\hline \multicolumn{2}{|c|}{ Mean Difference } & 4.19 & 4.26 \\
\hline \multicolumn{2}{|c|}{ t-value } & 1.89 & 2.58 \\
\hline \multicolumn{2}{|c|}{ df } & 20 & 22 \\
\hline \multirow{3}{*}{\multicolumn{2}{|c|}{ t_crit $(0.05 / 1)$}} & 1.72 & 1.72 \\
\hline & & (t Critical one-tail) & (t Critical one-tail) \\
\hline & & $\mathrm{H} 1: \mu 2>\mu 1$ & $\mathrm{H} 1: \mu 2>\mu 1$ \\
\hline
\end{tabular}


Table 4 shows the mean scores and $\mathrm{t}$-values for the decontextualized part in the pretest and post-test for the two groups. Mean score increases in groups
2 and 3 are approximately the same : 4.19 and 4.26 respectively. The increases are significant at the $5 \%$ level (using the one-tailed test).

Table 5: Results of the pretest and post-test: contextualized part / Group 2 \& Group 3

\begin{tabular}{|cc|c|c|}
\hline & & Group 2 & Group 3 \\
\hline \multirow{2}{*}{ Mean } & Pretest & 87.48 & 88.57 \\
& Post-test & 75.51 & 95.40 \\
\hline \multirow{2}{*}{ S.D. $\quad$ Pretest } & Post-test & 9.01 & 10.41 \\
& 7.20 & 2.24 \\
\hline Mean Difference & -11.97 & 6.83 \\
\hline \multicolumn{2}{|c|}{ t-value } & -4.41 & 3.22 \\
\hline Df & 20 & 22 \\
\hline \multirow{2}{*}{ t_crit $(\mathbf{0 . 0 5 / 1 )}$} & (t Critical one-tail) H1: & (t Critical one-tail) \\
& $\mu 2<\mu 1$ & H1: $\mu 2>\mu 1$ \\
\hline
\end{tabular}

The mean scores and $t$-values for the contextualized part on the pretest and post-test are shown in Table 5. The table shows that, in group 2, the -11.97 decrease in mean score is significant at the $5 \%$ level. In contrast, for group 3 , the 6.83 increase in mean score is significant at the $5 \%$ level.

The results then show that in group 2, which learned articles through the formfocused method, articles were produced more accurately on the measure assumed to require attention to form, and less accurately on communicative-based measures assumed to require more attention to context. In reverse, in group 3 , which focused on an integration of the form-based and function-based approaches, the subjects made some improvement on the decontextualized part, like group 2 , but a significant improvement in the contextualized part. The data then indicate an improvement in only form in group 2 but do show a strong trend toward higher accuracy in both form and function in group 3 . 
Table 6: Differences between the two groups before and after the experiment.

\begin{tabular}{|c|c|c|c|c|c|}
\hline & & $\begin{array}{l}\text { Post-test } \\
\text { Contex- } \\
\text { tualized }\end{array}$ & $\begin{array}{l}\text { Pretest } \\
\text { Contex- } \\
\text { tualized }\end{array}$ & $\begin{array}{l}\text { Post-test } \\
\text { Decontex- } \\
\text { tualized }\end{array}$ & $\begin{array}{c}\text { Pretest } \\
\text { Decontex- } \\
\text { tualized }\end{array}$ \\
\hline \multirow{2}{*}{ Mean } & Group 2 & 75.51 & 87.48 & 79.62 & 75.43 \\
\hline & Group 3 & 95.4 & 88.57 & 79.83 & 75.57 \\
\hline \multirow{2}{*}{ S.D. } & Pretest & 7.2 & 9.01 & 5.75 & 7.75 \\
\hline & Post-test & 2.24 & 10.41 & 3.81 & 7.67 \\
\hline \multirow{2}{*}{$\mathbf{N}$} & Group 2 & 21 & 21 & 21 & 21 \\
\hline & Group 3 & 23 & 23 & 23 & 23 \\
\hline \multicolumn{2}{|c|}{ t-value } & 12.61 & 0.37 & 0.14 & 0.06 \\
\hline \multicolumn{2}{|c|}{ df } & 42 & 42 & 42 & 42 \\
\hline \multicolumn{2}{|c|}{ t_crit $(0.05 / 2)$} & 2.02 & 2.02 & 2.02 & 2.02 \\
\hline
\end{tabular}

Table 6 offers evidence that the integrated approach is more effective than explicit grammar alone. The higher mean score of 95.4 in group 3 did not result from "an accidental assignment" (Woods, et al. 176) of the better subjects to the group. That means there is no difference between the two populations, but the fact that group 3 obtained a higher mean score than group 2 is due to a different approach to the acquisition of article usage.

From the analysis, the results of the posttest show that, in the contextualized part, when the mean difference between group 2 and group 3 is compared, the tvalue of 12.61 is significant at the $5 \%$ level. However, in the pretest of the contextualized part, the $t$-value of the mean difference is 0.37 , which is not significant at the $0.5 \%$ level.
For the decontextualized part, the $\mathrm{t}$-values for the pretest and post-test of the two groups are 0.06 and 0.14 respectively, which are both insignificant at the $0.5 \%$ level.

The results indicate that, in the pretest, there is no difference between group 2 and group 3 but there is a significant difference between group 2 and group 3 in the post-test.

The analysis then supports the expectation in that, due to the insignificant t-values, the two approaches do not seem to affect the learning acquisition of article usage for the decontextualized part. However, for the contextualized one, because of the significant $\mathrm{t}$-value, integration proves a superior approach to the explicit grammar approach. 
One notable point is that although both groups improved in the decontextualized part, the increased mean scores are not as high as that for group 3 in the contextualized part. This is probably due to the fact that it is vague and complicated to determine the use of articles in decontextualized items even among learners who have gone through form-based instruction.

The decreased scores in the contextualized part of group 2, whose learning focus was on explicit grammar may have been caused by too much focus on rules alone. Meanwhile, the subjects who gained an insight into article use from an integration of both implicit and explicit grammar improved significantly probably due to the concentration on both form and function.

This correlates with Widdowson's claim (1988) that learning grammar must incorporate both form and function because it enhances the intended meaning of a message. He states, "Learners need to realize the function of the device as a way of mediating between words and contexts, as a powerful resource for the purposeful achievement of meaning" (246).

\section{Suggested Pedagogical Procedures}

From the results of the experiment, it appears that an integration of implicit and explicit grammatical perspectives proves an effective approach for article teaching and learning.

The rationale behind this approach, as mentioned, lies in the fact that learners should know the form well and at the same time should be exposed to authentic materials (coherent texts) so that they can investigate the use of the grammatical aspect they are focusing on. They can have better insight into a specific grammatical point through textbased grammar instruction. The activities are designed so that the learner has maximized opportunities for real use. Nevertheless, the learner should not be totally excluded from explicit grammar as this type of grammar instruction can serve somewhat as a linguistic ground for the learner. There is, then, a relationship between grammar and communication, and there is an observation of both form and use. In this way, the learner can succeed in both language form and use. Concerning this notion, Widdowson (1988) notes, "A proper understanding of the concept of communicative competence would have revealed that it gives no endorsement for the neglect of grammar" (quoted in Lock (1996: 266)). Thus, explicit grammar can be provided in a meaningful context and it can be realized that grammar can be taught in an integrated fashion at both sentential and textual levels.

As the traditional approach to teaching articles is already widely known, the following part will demonstrate some techniques used in the function-based approach.

Exercises with contextualized materials can have several forms, such as gapfilling dialogues / texts, locating errors on articles in texts, cloze and discussions of the usage. All have the same purpose of interrelating form and function. 


\section{Example 1}

1. Look at the following. Extracts (a) and (b) are short film reviews from an Australian film review while (c) is part of a conversation between a doctor and a pregnant patient.

- Put the in the brackets where you think it is needed, or leave a blank if you think no article is needed.

a)

$$
\begin{aligned}
& \text { ( ) Tensions between ( ) } \\
& \text { three middle-aged couples } \\
& \text { after a blonde stranger } \\
& \text { arrives are explored in a } \\
& 1984 \text { Greek film. }
\end{aligned}
$$

b)

$$
\begin{aligned}
& \text { A hideous comic-book } \\
& \text { monster comes to ( ) life } \\
& \text { and terrifies a creepy house } \\
& \text { where a student lives. ( ) } \\
& \text { monster is scary but ( ) } \\
& \text { film is not. }
\end{aligned}
$$

c) Stella: l've only seen (...) midwife once.

Doctor: Right. Right. Okay. Did she explain to you what (...) 'case-load midwifery' involves?
Stella: That I would actually see her right from (...) beginning. [Doctor: $\mathrm{Mm}$ ] when she books me in, to (...) end, basically (...) delivery. She would hopefully deliver (...) baby if I wanted her to deliver it. Doctor: Mm.

\section{Observations}

- You probably found tensions and three middle-aged couples in A1(a) easiest to decide on. These do not need the because they are 'new' plural things in the text; they have not been mentioned before.

- In $\mathrm{A} 1(\mathrm{~b})$, the monster and the film are both already part of the text, they are already mentioned, so they take the. 
- In $\mathrm{A} 1$ (b) we have the expression come to life. This expression never has the before 'life' and can be learnt as a fixed form. The reason it never has the is that life is being used in a very general sense to refer to something abstract. Compare music, love, death, which are also often used in this way (e.g. 'I'm not afraid of death', 'Life without music would be nothing').

- In $\mathrm{A} 1$ (c) the is used to refer to single, specific things in relation to the situation: the midwife, the delivery, the baby and so on. When the reference is more general, countable nouns are put into the plural. 'Young babies need a lot of sleep.' You may be familiar with these types of rules for the use of the. In this unit we are going to explore more uses of the and try to make some new, more generally useful rules.

\section{Example 2}

Look at these examples of the use of the word $b o o k(s)$, taken from real spoken situations. In (a) there is $a$ (the indefinite article), in (b) there is the (the definite article) and in (c) there is no article.

a) [customer in a bookshop]

Customer: I'm looking for a book by Charles Handy, Schools as Organizations.

Assistant: Schools as Organisations, it might be in Educational.

b) [Another bookshop; this time the customer is unhappy. The shop does not have the book he is looking for.]

Customer: You don't have it? You never have the books I need.

c) [A small child is trying to tear abook. Her mother gets angry.]

Mother: No, no, that's horrible! You don't do that to books? 


\section{Observations}

- In general, the three rules above are very useful for a wide range of uses of $a$, the and no article.

- $A$ refers to one member of a class of things (e.g. 'She has a dog and a cat.') The refers to a thing or things that are assumed to be familiar to speaker and listener because they are limited or restricted in some way. In (b) above, the things referred to are only those specific books that a particular customer is likely to want.

- No article is used for open-ended reference to any or all members of a class (in the case of (c), all books the child might ever touch).

In this unit we look further at the use and non-use of articles, and some typical problems you may meet.

\section{Example 3}

In this passage of real speech, decide whether it is necessary to put the / a / no article in the gaps.
[Laura is talking about her friend, Melanie, who was looking for a parttime job.]

Laura: Well, no, Melanie's actually still a student and she has ten hours of lectures a week, so she works in McDonalds in her spare time, "cos she needs.......... money, and she works in McDonalds in Hatfield in ....... big shopping centre. In fact she wrote, she got $\ldots \ldots \ldots \ldots$. application form and sent it in, and she didn't hear from them, and we went to cinema ........... one day, and I said to her, 'Look, why don't you just go in and ask them?' 'Cos she wasn't on .......... telephone, you see. I said, 'They may well have been trying to ring you.' So she went in again and they couldn't find her application form, they gave her another one and fixed an interview with her at that time, so I think it was fact that she went back again...

(Adapted from Carter, Ronald et al, Exploring Grammar in Context.2000: $112,117,123$. 


\section{Example 4}

Collocations with $a$ / an, the, or - .

Fill in the following collocations with $a$ / an, the, or - (nothing).

1. He asked me to come in and take seat.

2. For time being my sister is working in a department store.

3. Silent movies have been out of date for many years.

4. Do you keep track of the long distance telephone calls you make each month?

5. That salesman never takes into account the fact that I am very busy.

6. In long run, this synthetic weave will wear better than the woolen one.

7. Keep___eye on my suitcase while I go to buy the tickets.

8. He is, on whole, a very diligent student.
9. She is the kind of person who always seems to be in hurry.

10. As soon as I get to Chiengmai, I'll drop you line.

11. He took advantage of their hospitality and stayed a whole month without paying them anything.

12. When I asked my brother whether he could go with us on a cruise he said that it was out of ___ question at this time of the year. 


\section{Conclusion}

As evidenced by the data, a significant improvement between pretest and posttest scores in the subject group whose learning strategies concentrated on both form and functions of articles proves that an integration of explicit and implicit grammar seems to enhance Thai learners' acquisition of English articles. The learning method is more satisfactory than learning the articles through explicit grammar alone.

Accuracy rates of article production for the subject group that went through the integration approach are significantly higher than the group that received only the form-based approach. The subjects that acquired the article system through explicit grammar did better on the decontextualized part but their performance on the contextualized part was not satisfactory. This could result from the fact they they know the rules well but when it comes to usage of articles in communication, they cannot really apply those rules. Meanwhile, the subjects who learned articles through an integration of explicit and implicit grammatical perspectives outperformed those in the other group. Their scores on the decontextualized part are somewhat better. However, their performance on the contextualized part improved significantly. The attainment of a higher accuracy level is probably due to the fact that the learners have access to both form and functions of the articles. The solid ground of these two aspects led them to a better understanding and correct usage of the English article system.
These findings are likely to be suggestive and could lead to future research on studies of other learning acquisition approaches to facilitate other syntactic aspects in English among Thai learners such as whether an integration of explicit and implicit grammar can be applied to the acquisition of other English grammatical categories and whether this type of integration produces better results than using only implicit grammar, not explicit grammar, as in this study.

It is hoped that the findings obtained in this study shed some light on the value of integrating both form and function in the study of the English article system. As each framework has its positive dimensions, rather than relying exclusively on explicit grammar, integration seems to strike a balance between form and meaning and leads to a positive systematic approach in the acquisition of the article system among Thai learners.

\section{Acknowledgements}

I would like to express my appreciation to the Faculty of Arts, Chulalongkorn University for funding this research. I am also deeply grateful to Assistant Professor Dr. Wirote Aroonmanakun for his invaluable advice and guidance on statistical matters. I am particularly thankful to Assistant Professor Prima Mallikamas and Michael Crabtree for their helpful comments on an earlier version of this paper. My special thanks are due to Raksangob Wijitsopon for teaching the control group. I would also like to thank (once again) Assistant Professor Prima Mallikamas, (once again) Raksangob Wijitsopon and Nida Darongsuwan, and for their help in administering the pretests. I am grateful, too, to Patavee Charnvivit, my research 
assistant. Last but not least, my thanks go to the students in the 4 groups, without whom I would not have obtained such valuable data. Any errors are my responsibility.

\section{References}

Allen, P., M.Swain, B.Harley and J. Cummins. 1990. 'Toward a More Comprehensive View of Second Language Education'. The Development of Second Language Proficiency, ed. by P.Allen, J. Cummins and M. Swain, pp. 57-81 Cambridge: Cambridge University Press.

Carroll, Suzanne, and Merrill Swain. 1991. Negative Evidence in Second Language Learning. Presented at the Second Language Research Forum, University of Southern California.

Carter, Ronald, Rebecca Hughes and Michael McCarthy. 2000. Exploring Gram-mar in Context. Cambridge: Cambridge University Press.

Christophersen, Paul. The Articles, A Study of Their Theory and Use in English. Copenhagen: Munksgaard and Oxford University Press, 1939.

Chun, Lee Yuk et al. 2001. 'Grammar Learning Materials for L2 University Classroom Use: From Theory to Practice.' Abstracts Presented at $36^{\text {th }}$ RELC International Semenar, Singapore, April.

Dušková, Libǔse. 1969. 'On Sources of Errors in Foreign Language Learning.' Inter-national Review of Applied Linguis-tics. Vol.7, No.1: 11-36.

Eastwood, John. 1999. Oxford Practice Grammar. Oxford: Oxford University Press.

Ellis, R. 1995. 'Interpretation for Grammar Teaching.' TESOL Quarterly. Vol.29, No.1: $87-105$.

Givón, T. 1984. Syntax A FunctionalTypological Introduction. Vol.1, Philadelphia: John Benjamins Publishing Company.

Harley, Birgit, and Merrill Swain. 1984. 'The Interlanguage of Immersion Students and Its Implications for Second
Language Teaching.' Interlanguage, ed. by Allen Davies et al., pp. 38-55 Edinburgh: Edinburgh University Press.

Huebner, T. 1983. A Longtitudinal Analysis of the Acquisition of English. Ann Arbor: Karoma Publishers.

Hung, Joseph. 2001. 'Form, Meaning and Use in Pedagogical Grammar: A Language Awareness (LA) Perspective.' Presented at $36^{\text {th }}$ RELC International Seminar, Singapore, April, 2001.

Johns, Tim. 1994. 'From Printout to Handout: Grammar and Vocabulary Teaching in the Context of Data-Driven Learning.' Perspectives on Pedagogical Grammar, ed. by Terence Odlin, pp. 293-313 Cambridge University Press.

Kennedy, Graeme D. 1990. 'Collocations: Where Grammar and Vocabulary Teaching Meet.' Language Teaching Methodology for the Nineties, ed. by S. Anivan RELC Anthology Series. No. 24: 215-229. Singapore: Singapore Regional Language Centre.

Kok, Lim King. 'Difficulties of Malay Students in Learning Subject-Verb Agreement and the System of Articles.' Presented to Regional Language Centre, Singapore (July 1985 - March 1986).

Krashen, Stephen. 1985. The Input Hypothesis: Issues and Implications. London: Longman.

Lee, Winnie and Emily Yan. 2001. 'Grammar Learning Materials in L2 University Classroom Use: From Theory to Practice.' Presented at $36^{\text {th }}$ RELC International Seminar, Singapore, April, 2001.

Lekawatana, Pongsri, et al. 1968. A Contrastive Study of English and Thai. Ann Arbor: The University of Michigan.

Lightbown, Patsy M. and Nina Spada. 1995. 'Focus-on-Form and Corrective Feedback in Communicative Language Teaching.' Readings on Second Language Acquisition, ed. by $\mathrm{H}$. Douglas Brown and Susan T.Gonzo, pp. 306-330 New Jersey: Prentice Hall Regents. 
Little, David. 'Words and Their Properties: Arguments for a Lexical Approach to Pedagogical Grammar.' Perspectives on Pedagogical Grammar, ed. by Terence Odlin, 99-122. New York: The Press Syndicate of the University of Cambridge.

Little, D., S. Devitt and D.Singleton. 1989. Learning Foeign Language from Authentic Texts. Dublin: Authentik, in asociation with CILT, London.

Lock, G. 1995. 'Doers and Causers.' New Ways in Teaching Grammar, ed. by M.C. Pennington, pp. 126-133 Virginia: TESOL.

Lock, G. 1996. Functional English Grammar. Cambridge: The Press Syndicate of the University of Cambridge.

Master, Peter. 1994. 'The Effect of Systematic Instruction on Learning the English Article System.' Perspectives on Pedagogical Grammar, ed. by Terence Odlin, pp. 229-252. Cambridge: Cambridge University Press.

Menachem, Dagut and Laufer Batia. 1983. Second Language Learning, ed. by Betty Wallace Robinett and Jaequelyn Schachter, pp. 19-41. Ann Arbor: The University of Michigan Press.

Montgomery, C. \& M. Eisenstein. 1985. 'Reality Revisited: An Experimental Communicative Course in ESL.' TESOL Quarterly. Vol.19, No.1 (1985):317-334.

Murugaiyan, N. 2001. 'Grammatical Theory for Teacher Development and Effective Classroom Instruction.' Presented at $36^{\text {th }}$ RELC International Seminar, Singapore, April, 2001.

Odlin, Terence. 1994. 'Introduction.' Perspectives on Pedagogical Grammar, ed. by Terence Odlin, pp. 122. Cambridge University Press.

Parrish, B. 1987. 'A New Look at Methodologies in the Study of Article Acquisition for Learners of ESL.' Language Learning. Vol.37 (1987): 361393.

Pongpairoj, Nattama. 2002. 'Thai University Undergraduates' Errors in English Writing.' Journal of Language and Linguistics. Vol.20, No.2 (January-June 2002):66-99.
Quirk, Randolph et al. 1972. A Grammar of Contemporary English. London: Longman.

Richards, Jack C. 1996. Preface. Functional English Grammar. By Graham Lock. Cambridge: The Press Syndicate of the University of Cambridge.

Schachter, Jacquelyn. 1991. 'On the Issue of Completeness in Second Language Acquisition.' Second Language Research. Vol. 6(1991):93-124.

Schachter, Jacquelyn and Marianne CelceMurcia. 'Some Reservations Concerning Error Analysis'. Second Language Learning, ed. by Betty Wallace Robinett \& Jacquelyn Schachter, pp. 272-284. Ann Arbor: The University of Michigan Press.

Sinclair, J. McH. 1985. 'Selected Issues.' English in the World. Cambridge: Cambridge University Press.

Srioutai, Jiranthara. 2001. 'Viewing and Teaching the English Articles Semantically.' Bulletin of the Faculty of Arts Chulalongkorn University. Vol. 30, No.2 (July-December 2001): 151-167.

Spada, N. 1987. 'Relationships between Instructional Differences and Learning Outcomes: A Process-Product Study of Communicative Language Teaching.' Applied Linguistics. Vol.8 (1987): 137161.

Sunaryo, Al Hikmah, 2001. 'Returning to Explicit Grammar Instruction to Keep the Balance between Accuracy and Fluency.' Presented at $36^{\text {th }}$ RELC International Seminar, Singapore, April, 2001.

Tarone, Elaine and Betsy Parrish. 1995. 'Task Related Variation in Interlanguage: The Case of Articles.' Readings on Second Language Acquisition, ed. by $\mathrm{H}$. Douglas Brown and Susan T. Gonzo. New Jersey: Prentice Hall Regents.

Thomson, A.J. and A.V. Martinet. A. 1980. Practical English Grammar. Oxford: Oxford University Press.

Ubol, Charas. 1988. 'Error Analysis: To Translate It into Practical teaching.' Presented at the International Symposium on Language and Linguistics, Bangkok, August 1988. 
Widdowson, H. 1988. 'Grammar, Nonsense, and Learning.' Grammar and Second Language Teaching, ed. by W. Rutherford \& M. Sharword Smith, pp. 232-254. New York: Newbury House.

White, Lydia. 1991. 'The Verb-Movement Parameter in Second Language Acquisition.' Language Acquisition. Vol.1, No.4 (1991):337-60.

Woods, Anthony, Paul Fletcher and Arthur Hughes.1986. Statistics in Language Studies. Cambridge: Cambridge University Press.

Yip, Virginia. 1994. 'Grammatical Consciousness-Raising and Learnability.' Perspectives on Pedagogical Grammar, ed. by Terence Odlin, pp. 123138. New York: The Press Syndicate of the University of Cambridge.

Yotsukura, S. 1970. The Articles in English: A Structural Analysis of Usage. The Hague: Mouton. 


\section{Appendix I}

\section{Pretest}

\section{Articles}

(30 minutes)

I. Fill in the blanks with $a$, an, the, or-(nothing).

1. He worked as photographer.

2. woman in next apartment is Japanese.

3. human beings live in society.

4. Before invention of computer, working was much slower.

5. When I studied at university. I had lots of friends.

6. musician is instrument. person who plays musical

7. Himalayas are located in Nepal.

8. She's very keen on cooking Italian food.

9. You've got

10. The man was elected dark hair.

11. cassettes cost less than President.

12. There was TV program about _ dangers to environment.

13. " dog is only thing on earth that loves you more than you love yourself." John Billing.

14. I really want to go to North Pole!

15. “ Americans like "women!" Russell Baker.

16. My cousin's got

17. “ death is fat books and thin slow down." Anonymous.

18. Would you like to join

19. If a black cat walks past you in bad luck.

20. My family prefers living in prominent nose. nature's way of telling you to

21. The doctor recommended that I stay in country, not in a city.

22. She graduated from

23. What 's on Oxford University.

24. piano is one of the nicest instruments to play.

25. "Without music, life would be mistake."Anatole France. 
II. Decide which word or words are correct.

1. I think that's awful thing to say.
a) an
b) -
c) the

2. I don't know what to do. It's quite
a) -
b) the
c) $a$

3. golf is my favourite sport.

4.
a) -
b) $\mathrm{A}$
c) The difficult problem.
a) -
b) $\mathrm{A}$
c) The school starts at

5. Robert opened a drawer and took out
a) -
b) a
c) The photos.

6. We can finish the rest of the bread for
a) -
b) a
c) The

7. I might listen to radio.
a) a
b) -
c) the

8. We need to protect environment from pollution.
a) -
b) an
c) the

9. The news is on radio now.
a) -
b) a
c) the

10. I've got pain in my back. It really hurts.
a) -
b) a
c) the

\section{Complete the conversations. Put in a/an or the.}

1. Laura: Look outside. The sky is getting very dark.

Trevor: I I hope there isn't going to be breakfast.

2. Mike: I'm going out for walk. Have you seen my shoes?

Harriet: Yes, they're on floor in kitchen.

3. Tom: I didn't know Melanie had __ dog.

David: It isn't hers. She's just taking it for a walk while owner is away.

4. Andrew: Guess what. I found pavement this morning.

Jessica: You really ought to take it to police station, you know.

5. Herry: Would you like cigarette?

Nick: $\quad$ No, thanks. I've given up smoking. It's bad habit.

6. Matthew: Is this

Emma: Yes, it's book you were telling me about?

Matthew: What did you say it's about?

Emma: I knew you weren't listening to me. It's science fiction story. It's about the beginning of universe. 


\section{Complete this true story. Put in a/an or the.}

A man decided to rob (1) __ bank in the town where he lived. He walked into one of (4)

(2) bank and handed (3) note to note, which told her to give (7) cashier read (6) he might have (8) man some money. Afraid that man then walked out of (10) gun, she did as she was told. (9)

note behind. However, he had no time to spend (12) money because he was arrested (13) mistake. He had written (15) same day. He had made (14)

back of (17) ___ envelope. And on (18) . note on (16)

envelope was his name and address. This clue was quite enough for (20) detectives on the case.

( Parts $3 \& 4$ are adapted from Eastwood, Oxford Practice Grammar. 1999: 196-7.) 


\section{Appendix II}

\section{Post-test}

\section{Articles}

(30 minutes)

I. Fill in the blanks with $a$, an, the, or-(nothing).

1. vegetables on that stand are fresh every day.

2. There are several new books on shelf in library.

3.

4. honey is made by French defeated bees.

5. I have plenty of

6. All full of time. Germans.

7. fire which destroyed summers in life. third floor.

8. He isn't professional musician but he plays _ piano well.

9. This morning sitting across from me on sailor was showing soldier.

10. Is there sailor and soldier were street-car; picture of his wife to

11. Do you usually eat

12. Hudsons own oven in kitchen?

\section{Suthep.}

13. Mr. Allison does not like

14. There is some paper and desk in my room. on

15. We like to study
16. These vegetables are good for egg for breakfast? summer cottage at ___ Doi

17. I enjoyed speech of cream in his coffee. bottle of ink in radio last night. He spoke about Prime Minister health.

on Philippines. geography. in Philippines. situation 


\section{Circle $a, b, c$ or $d$ which is the best answer.}

1. a. Bell invented the telephone nearly a hundred years ago.

b. Bell invented the telephone nearly hundred years ago.

c. Bell invented telephone nearly a hundred years ago.

d. Bell invented telephone nearly the hundred years ago.

2. a. During long vacation he spent the week with his parents.

b. During the long vacation he spent the a week with his parents.

c. During long vacation he spent the a week with his parents.

d. During the long vacation he spent a week with his parents.

3. a. She explained it in German the better than I could.

b. She explained it in the German the better than I could.

c. She explained it in the German better than I could.

a. She explained it in German better than I could.

4. a. Woman who is standing over there is wife of our boss.

b. A woman who is standing over there is wife of our boss.

c. The woman who is standing over there is the wife of our boss.

d. The woman who is standing over there is wife of our boss.

5. a. Passing lorry made a noise which woke us up.

b. Passing lorry made the noise which woke us up.

c. A passing lorry made the noise which woke us up.

d. A passing lorry made noise which woke us up.

6. a. A boy who was once at this school is now a clerk in the French Embassy.

b. A boy who was once at this school is now clerk in the French Embassy.

c. A boy who was once at this school is now a clerk in French Embassy.

b. A boy who was once at this school is now clerk in French Embassy.

7. a. A gold melts at a lower temperature than an iron.

b. Gold melts at a lower temperature than iron.

c. Gold melts at the lower temperature than an iron.

d. Gold melts at lower temperature than an iron. 
8. a. The woman he married is a daughter of a manager of the company.

b. The woman he married is daughter of a manager of a company.

c. The woman he married is the daughter of manager of the company.

d. The woman he married is the daughter of the manager of the company.

9. a. I bought jacket I am wearing today a year ago.

b. I bought a jacket I am wearing today the year ago.

c. I bought the jacket I am wearing today a year ago.

d. I bought the jacket I am wearing today the year ago.

10. a. The people who lived here before us planted most of the flowers in our garden.

b. The people who lived here before us planted most of flowers in our garden.

c. People who lived here before us planted most of flowers in our garden.

d. A people who lived here before us planted most of the flowers in our garden. 


\section{Complete the conversations. Put in a/an or the.}

1. Sarah : What's your brother doing now? Has he got

........... good job?

Laura : Yes, he's .............. soldier. He's in .... arm: He loves it. It's great life, he says.

2. Mark : Why were you late for your meeting? Sarah : Well, first I had to go to ......... hotel I'd booked into. I took ........ taxi and ......... driver got completely lost. It was .......... terrible nuisance. man was complete idiot.

3. Melanie : Would you like tomato? There's one in fridge.

David : Oh, yes, please. I'll make myself cheese and tomato sandwich.

4. Rita : I've got ............ problem with my phone bill. Cal I see someone about it?

Receptionist: Yes, go to the fifth floor. Take elevator alor the corridor.

\section{Complete the following story. Put in a / an, the or - (nothing).}

(1) people can make silly mistakes. This happened quite (2) ............. long time ago-in (3) 1979 , in fact. (4) scene was (5) old people's home in (6) ........... small town in (7) .......... North of England called (8) ........... Otley. The owners of the home wanted to put (9) ........... fence around it to make it more private. (10) ......... work began soon after (11) .......... Christmas when (12) ............ workmen arrived in (13) ........... lorry with planks of wood they put up around the building. 'It was (14) very nice fence,' said one of the old people. But there was (15) .......... problem. The workmen forgot to leave (16) .......... gap for the lorry to drive out through. They had to come back the next day to knock down part of (17) ........... fence. 'What (18) ............ silly mistake!' said another resident. 'It was so funny we had to laugh. In fact it was (19) ........... most fun we've had for (20) long time.'

(Parts $3 \& 4$ are adapted from Eastwood, Oxford Practice Grammar. 1999: 197, 199, 214-5.) 